\title{
SANITATION AND TELEPATHY: GEORGE ELIOT'S THE LIFTED VEIL
}

\author{
By Derek Woods
}

To consider the sewer as the antecedent to the stream of consciousness is almost commonsensical, since to do so is really only to literalize the stream of consciousness for a modern urban setting, where there are few streams other than those in the sewer, and where the sewer flows everywhere, underground and unseen.

—Michael Rubenstein, Public Works

THE GREAT STINK OF LONDON took place one year before the publication of George Eliot's The Lifted Veil (1859). As a peak sanitary crisis, the Great Stink helps us to understand the particular telepathy of Eliot's narrator, since The Lifted Veil combines the rhetoric of telepathy with that of a more threatening form of transmission among bodies: foul odor and contagious air. Throughout the figurative structure of Eliot's story, tropes that convey the narrator's ostensibly supernatural experience contain traces - sometimes cryptic, sometimes explicit - of the earthly matter of sanitary crisis. The first section of this essay explores the sanitary dimension of The Lifted Veil, linking the story to sanitary crisis and to Victorian materialist psychology - particularly the work of George Henry Lewes - which conceived mind in physical terms. With the role of sanitation established, the second section shows the importance of the sense of smell to Latimer's first-person narration of telepathy. This section outlines the transition, contemporaneous with sanitary reform, from the use of animal to the use of vegetable perfumes. Throughout the story, vegetable scents act as prophylaxes against the narrator's too-physical telepathy. From these readings, it becomes clear that Eliot writes "extrasensory" perception with recourse to sensory figures. Telepathy and sanitation overlap in this exceptional gothic science fiction in such a way as to demand a new concept of olfactory telepathy.

Telepathy is F. W. H Myers's 1882 name for phenomena that were, in 1859, understood as animal magnetism and clairvoyance. Beryl Gray, Helen Small, and Martin Willis explore this context of The Lifted Veil, establishing Eliot's interest in the phenomena during the 1850s. Eliot's interest in telepathy became, as Nicholas Royle puts it, "less practically oriented" as a result of her relationship with the skeptic George Henry Lewes - yet it remains throughout her work (86). ${ }^{1}$ The influence of Lewes is one reason why telepathy appears in a naturalistic rather than a supernatural frame in the story. When Eliot's narrator, Latimer, first begins to experience telepathy after an illness, his extra sense has the quality of a curse rather than a gift, since it reveals too much to him: the true thoughts of his companions and ultimately of 
his wife Bertha, whom he is able to love only so long as her thoughts are opaque. ${ }^{2}$ Thus the plot of The Lifted Veil hinges on two unveilings: first that of Bertha herself, and later, in a macabre scene, that of Bertha's servant. Restored to life by a blood transfusion, the servant reveals Bertha's plan to poison Latimer. In relation to sanitation and materialist psychology, the most important passages are Latimer's descriptions of telepathy, which most clearly show the story's paradoxical naturalism. ${ }^{3}$ Throughout the story, telepathy is an extrasensory sense that depends as much on physical proximity as on non-local, mystic messaging. This very material species of telepathy stages medical threats of contagion and social anxieties about sanitation.

Criticism on The Lifted Veil settles into roughly two kinds of interpretation. The first, which includes the earliest articles on the story, is formalist and aesthetic. Critics such as Carroll Viera and Julian Wolfreys discuss Latimer's telepathy as a comment on narrative and authorship. In these readings, it is less important what telepathy means at the level of the text's content. In the second category, Beryl Gray, Martin Willis, Diane Mason, Kate Flint, and others read Latimer's telepathy allegorically. For these critics, since telepathy is a pseudoscientific and supernatural phenomenon, Eliot's attention to it must be about something else. Treated allegorically, telepathy is about disciplinary practices surrounding "masturbatory insanity" (Mason 399), penetrative visual knowledge of the body (Flint 45760), or financial speculation (Willis 145-61). These essays read telepathy in a naturalist frame, but they assume that naturalism makes it impossible to take telepathy literally. Other essays in this category do take Latimer's telepathy literally. Since Beryl Gray's 1982 article, for example, critics have explored the story's history-of-science context in some detail and with reference to debates on mesmerism. Such essays take Latimer to be a reliable narrator, understanding the story not as allegory, but as a story about telepathy for its own sake. They examine telepathy in a supernatural frame, whether as a "pseudoscience" (Gray 410), or as a genuine gothic theme with implications for literary theory (Royle).

My essay combines these latter two approaches to The Lifted Veil, a text at once naturalist and gothic. ${ }^{4}$ Eliot's story is best understood as a literal treatment of telepathy in a naturalist frame. Sanitary crisis and mid-Victorian debates about the materiality of mind, in combination with Latimer's olfactory telepathy, create a figurative structure the overall effect of which is a paradoxical naturalism. ${ }^{5}$ The paradox emerges from the combination of the language of sanitation and disgust with the sense of smell in Latimer's characterizations of his telepathic experience. His experience is utterly paranormal and never exposed as a hoax within the storyworld, but he describes it in terms that seem to reduce it to the most material of senses. This naturalism that re-signifies the supernatural as natural without reducing it away is thus non-reductive. It is a naturalism concerned with explaining mind as physical, yet without reducing it to "mere" matter and without assuming that the smallest physical scales are the only real ones. For this reason, Eliot's paradoxical naturalism shares much with Lewes's theory of the body-mind relation, discussed below, and also with recent forms of materialism influenced by quantum theory, chaos theory, and the study of self-organization. ${ }^{6}$

Critics have shown that body-mind dualism is not tenable in Eliot's work or in the work of her scientist companion, George Henry Lewes (Shuttleworth 2001, xxi-xxii; Rylance 260-61). The relation of psychology and physiology and the implications of studying mind and soul in a materialist frame were a constant preoccupation for Lewes. Below, examples from The Physiology of Common Life (1859) and Problems of Life and Mind (published in three series in 1874,1877 , and 1879) clarify the precise meaning that this preoccupation 
has for The Lifted Veil and for my concept of olfactory telepathy. But in the midst (and mist) of London's sanitary crisis, the implication of naturalistic telepathy is that mind is just as open as body to contamination by a threatening environment. Eliot's experiment in the involuntary removal of barriers to sympathy - in the form of Latimer's telepathy - becomes an experiment in the linked rhetoric of sanity and sanitation. In The Lifted Veil, this link is more than etymological. The disgust-inducing context of the story's writing shapes its figurative structure, so that Latimer's "crack-brained" telepathy entails the physical mixture of bodies-minds (33). In short, the stream of consciousness leaks.

The Lifted Veil can inform our thinking on the relation of body, mind, and environment insofar as that relation is a problem of writing inextricable from literary history. Latimer's telepathic sympathy thus proves helpful to the work of writing and re-writing bodymind dualism. The Lifted Veil and the present essay engage the implications of Lewes's commitment, in the words of Rick Rylance, to "remake the language of psychology ... on the assumption of body-mind identity," to create or discover a language "in which there is seamless movement between the physical and the mental" (270; 285). The Lifted Veil does not succeed in discovering this language - in fact, no one has discovered it, which is what makes the "hard problem" so hard. Without presuming to erase the seams between mind and body, however, Eliot's gothic experiment in the relation between telepathy and sanitation does figurative work to strain them. Indeed, the patterned repetition of these distinctions should itself be of interest for researchers in psychology, neuroscience, and the philosophy of mind. The Lifted Veil reflects upon the repetition of body-mind distinctions as an irreducible problem of language and enacts this problem further by asking how it varies in historically specific environments and atmospheres, such as London in the Great Stink. The story leaves us with a theory of mind that takes the coupling of organism and environment as its starting point.

\section{Latimer's Telepathy and the Great Stink of London}

IN ONE OF HIS EARLIEST DESCRIPTIONS of telepathy, Latimer figures the minds of his companions as piles of excrement. This point goes unacknowledged in commentary on The Lifted Veil, but in the context of the Great Stink, the "fermenting heaps" in the passage below are easily identified as dung heaps. This early image is perhaps the nadir of The Lifted Veil, read by Thomas Albrecht as "a crisis for Eliot's ethics of sympathy" (440). The passage begins with the much-discussed trope of (scientific) knowledge as penetrative vision:

\footnotetext{
the rational talk, the graceful attentions, the wittily-turned phrases, and the kindly deeds, which used to make the web of their characters, were seen as if thrust asunder by a microscopic vision, that showed all the intermediate frivolities, all the suppressed egoism, all the struggling chaos of puerilities, meanness, vague capricious memories, and indolent make-shift thoughts, from which human words and deeds emerge like leaflets covering a fermenting heap. (14)
}

In this passage, Latimer first sees inside the minds of his family members. He figures this vision as prosthetic, invasive, and intensely physical: the microscope analyzes and disperses words and manners, leaving only direct experience of the underlying thoughts and emotions of his interlocutors. But as Kate Flint makes clear in her reading of The Lifted Veil, in light of contemporaneous physiology these thoughts and emotions are not mental or spiritual, but 
material (457-60). In Latimer's self-narration of telepathy, language falls away, exposing the physiology of consciousness as a rotting dung heap. In the absence of any incorruptible soul, and perhaps also of thoughts irreducible to matter, this excremental body anticipates its future as waste. ${ }^{7}$ Language becomes a prophylaxis against the actual content of other "minds." The "leaflets" that represent human words and deeds cannot contain the unsanitary presence of the heap. The mannered and rhetorically textured speech that mediates social interaction seems, for Latimer, to cover a decaying matter of embodied thoughts and emotions. Latimer's involuntary telepathy does transmit the thoughts of those with whom he comes into contact, but it transmits them as abject objects of disgust.

Latimer identifies the embodied minds in his immediate environment with a use of urban space that, in London, had reached a moment of historical crisis by the end of the 1850s. Such heaps of human and animal waste were epidemiological threats, both through their microbial realities and through the threat of contagious miasma. Reading the dung heap passage, Flint compares its optical conceit with a remarkable passage from Lewes's Physiology of Common Life, where Lewes imagines an impossible observer who would be able to follow a person's blood through the complexity of its entire systemic flow - rather like the tiny observers who travel by submarine in the film The Fantastic Voyage (1966), or like Mr. Tompkins in science writer George Gamow's Mr. Tompkins Inside Himself (1967). ${ }^{8}$ In these texts, the "mind's eye" is the figurative sense that mediates this experience of the microscopic interior of bodies. Yet the dung heap passage does not end with the figurative sense of sight. As is often the case in Eliot's story, more than one sense organ comes into play as a figure of extrasensory experience.

"Fermenting heap" signifies odor rather than vision - all the more so because in Eliot's image the leaflets "cover" the heap, blocking it from view just as the "image" reveals it. It is an image easier to imagine as odor than as visualization, as the passage ends with the hidden-but-present matter of biological waste. This olfactory dimension of Latimer's telepathy, discussed at length in the next section, shows that The Lifted Veil is much less focused on the sense of sight than the emphasis of its commentators would suggest. The early odor-image registers the influence of London's sanitary crisis and begins a pattern that repeats throughout Latimer's descriptions of telepathic experience.

In June 1858, just over a year before Eliot published her story in Blackwood's Edinburgh Magazine, London experienced an extended heat wave. The smell of human waste inundated the city more strongly than ever before. London's recently built sewers either clogged or emptied into the Thames, but at a location where the river's tides failed to sweep away their sewage. This powerful two-week period of olfactory history came to be known as the Great Stink of London. It inspired a major outcry from Londoners, who feared the spread of disease. The Great Stink even impacted the riverside parliament, affecting some of the most wealthy and powerful citizens; according to Stephen Halliday, Benjamin Disraeli was seen "fleeing from the chamber, handkerchief to nose" (ix). The Great Stink marks a moment of transition, when technologies of urban sanitation had yet to catch up with population growth and changing values concerning the relation between hygiene and social status. ${ }^{9}$

The sickening effects of Latimer's open body-mindedness tie The Lifted Veil to the history of sanitary reform. Several historians point to Edwin Chadwick's Report on the Sanitary Condition of the Labouring Population of Great Britain (1842) as the substantial beginning of this political and demographic process. Michelle Allen notes that Chadwick's work helped to shape the influential health legislation passed in 1848, including the Public 
Health Act, Nuisances Removal and Disease Prevention Act, and the Metropolitan and City Sewers Act (30). Of central importance to Chadwick's report was the careful collection of population-level statistics. Sanitary reform is one of the earliest examples of the form of power and sociality that Michel Foucault calls "biopolitics." For Foucault, Chadwick's efforts were one part of a "project of a technology of the population," for which demographic statistics on rates of birth, death, disease, and living conditions were essential (171). Sanitary reform led to what Foucault describes as a "program of hygiene as a regime of health for populations" and involved "authoritarian medical interventions and controls" (175). Eliot wrote The Lifted Veil in a moment when sanitary reform had reached an intense pitch. New norms and disciplines of the body reshaped both the public and private spaces of London. In 1858 , however, these reforms were still in process. As Michelle Allen notes, the infrastructure of the Thames embankment, approved in the aftermath of the Great Stink and completed in 1873, piped sewage far enough downstream that it would be swept away by the tide (67). It also eliminated the river's Dickensian mudflats. Social mores around hygiene were changing, but sanitary reform had not yet had a significant influence on London's atmosphere. The Lifted Veil emerges from the worst modern crisis in London's infrastructural capability to deal with human and animal waste.

Sanitation is one of the central (infra)structural transformations in global biopolitics, a spatial intervention and a form of soft power quickly internalized by individuals. Chadwick was not a physician, but rather a lawyer and bureaucrat who once worked as Jeremy Bentham's secretary - a point which furnishes a connection to Foucault's work on the prison in Discipline and Punish. Chadwick even disliked physicians, considering a profession with disease as its livelihood to be part of the problem. He considered his own efforts scientific and rational, yet the sciences of importance were engineering and statistics rather than medicine or biology. As Choi points out, social and actuarial statistics "collaborated most publicly and spectacularly in the late 1830s and early 1840s"; Chadwick's Report included a detailed statistical analysis of disease, mortality, and life expectancy for all regions of the British isles, subdividing the population "by geography, occupation, age, and sex," and offering "firsthand testimony about living conditions from local inspectors and officials" (572). London's crisis seems to have been amplified by the overlap of miasma theory's last days with the new fastidiousness of sanitary reform and the increased population density brought about by industrialization. The Great Stink came at a time when the miasma theory of disease was at once the medically-standard and the popular approach to etiology. Miasmas had only begun to be discredited by figures such as John Snow. In an early example of germ theory, Snow's analysis of the 1854 Soho cholera epidemic showed that water from the Broadwater pump had spread the disease (Gilbert 87-90). Germ theory had begun to gain credence in medical and intellectual circles, but Snow was unable to isolate the microbial source of infection. Though he was skeptical of miasma theory, he was far from divesting London of its standard etiology. In the 1850s, most still assumed that bad air was a cause of disease, that it could be inhaled, and that the presence of foul odors signaled the risk of infection.

As Kirstie Blair notes, sanitary reform was dependent on the notion that disease was environmental, not contagious (146). Germ theory gained broad acceptance in the medical community only in the 1870s, as a result of the work of Louis Pasteur in France and Robert Koch in Germany. When a crisis similar to the Great Stink stirred Paris in 1880, the relatively delayed response can be attributed, at least in part, to the spread of germ theory. As David 
Barnes argues, the miasma-fearing English were quick to respond to their olfactory crisis with "an unprecedented public-works project to rid London of its shit"; but on the other side of the channel the "odours of Paris' continued to visit the city periodically into the early twentieth century" (103-05). The crises in Paris and London shared much in their material conditions and in the alarmed responses of their populations. The question is, why did the authorities in Paris do so little by comparison with the English? Barnes's counterintuitive answer is that germ theory actually prevented a decisive response, in part because the cause of disease had become controversial and the path from theory to practice was unclear (121). By 1895 , when a similar stench hit Paris, the response was more subdued. Odor itself did not signal the same degree of pathological danger that it had in 1858; odor could no longer spread disease, the causes of which were, for reformers, increasingly localized. With germ theory, as Barnes argues, "demonstrable and measureable infection... took the place of the more diffuse, impressionistic 'infection' ... of the Great Stinks" (123). The Great Stink of London was a dramatic event because it came at a very particular moment of overlap in the histories of medicine and sanitation. Sanitary reform had already disseminated the image of a sterilized, hygienic modernity along with new bodily disciplines and norms. But the germ theory of disease had not yet distinguished between the danger of foul odor and the danger of its sources.

London's sanitary crisis and the attendant class politics of hygiene connect directly to Marian Evans's biography. If historians of the Great Stink are correct, living in London and avoiding its filth at the same time was not possible for any but the wealthiest Londoners, if even for them. Many travelled to escape the summer stench. Evans and Lewes spent the summer of 1858 in Europe. Since both were often in poor health during their years in London, Evans and Lewes often left the city for the country. There is evidence that London's pollution was a motivation for these travels. In a letter to Cara Bray written in June 1857 that year, Evans "could have wished myself at Richmond in this hot weather for the sake of seeing you, but no pleasure short of that could have made me wish to be in the hazy atmosphere of London environs. Richmond is not fascinating in 'the season' or through the summer - it is hot, noisy, and haunted with cockneys" (Haight 2: 338-39). Several letters written between 1857 and 1860 give a negative description of London and of Evans's and Lewes's domestic space. In July 1859, Evans wrote that she "should like to transfer our present house, into which we were driven by haste and economy, to some one who likes houses full of eyes all around him. I long for a house with some shade and grass close round it" (Haight 3: 118). To this reference to population and over-proximity, we can add the fact that their new neighborhood was only a few blocks from the Thames and no doubt within smelling distance. The couple later moved to St. Johns Wood, a suburb of London popular with Victorian artists and intellectuals who wanted to escape the bad air of London. ${ }^{10}$

Through Evans's habitat, it seems, sanitary crisis influences the figurative structure of The Lifted Veil. Latimer's lack of prophylaxis between himself and the minds in his environment parallels Evans's distaste for "cockneys" and her desire for thicker, preferably vegetable boundaries between self, domus and public spaces polluted by noise and waste. The Lifted Veil registers this contemporaneous class politics of sanitation through Latimer's narration of telepathy as the unsanitary transmission of embodied thoughts.

By the 1850s, the state of positivist and materialist science was such that many of Eliot's contemporaries came to see body and mind as inseparable, or to see mind as altogether reducible to body, or to question the existence of an immaterial mind or soul. ${ }^{11}$ Physiology extended its explanatory power to psychology. By 1858, the scientific debate concerning 
the existence of mind separate from the observable body was both thriving and complex. ${ }^{12}$ As critics such as Sally Shuttleworth and Rick Rylance have shown, Eliot's fiction links the narration of interior consciousness to this ongoing debate. For Kate Flint, Eliot's story "would have been impossible without Lewes's physiological researches, and in many respects her work should explicitly be seen as a dialogue with them" (458).

Lewes's Physiology of Common Life shows his deep concern with the relationship between physiology and psychology, a concern that intensifies in Problems of Life and Mind, which Eliot completed after his death. The second volume of Physiology opens with a discussion of what philosophers of mind call the "hard problem": the relation between consciousness and the brain. ${ }^{13}$ Published in the year following the Great Stink, the first volume of Lewes's Physiology includes a chapter on breathing and respiration that spends considerable time on the dangers of bad air and of suffocation in confined, poorly ventilated, or overcrowded spaces, concluding with a section entitled "How We Adapt Ourselves to Bad Air." Lewes goes on to make connections between respiration and thought itself: "if it is true that all vital activity increases the amount of carbonic acid exhaled ... we may readily believe that intellectual fatigue, and the lassitude which succeeds mental or emotional excitement, will be accompanied by a corresponding depression of the respiratory function" (398-99). This is Lewes's answer to the question of why philosophers sigh when they are thinking very hard (399). But here the inverse is also true: bad air affects thought. Lewes's focus on the materiality of air makes it seem a threat to the embodied mind, reminding us that "this air, which no man can see, is nevertheless a very material substance" (353). ${ }^{14}$ Lewes's emphasis on the materiality of air parallels his emphasis on the materiality of mind. But his first concern in writing about air and respiration - the one with which he opens and to which he returns throughout the chapter - is with the role of ventilation in sanitary reform. The juncture of these two points is characteristic of The Lifted Veil and its concern with the unsanitary materiality of what seems a most immaterial, supernatural form of thought transmission.

A striking passage from The Problems of Life and Mind illustrates the commingling of physiological and psychological systems and their openness to environmental influence. While Problems presents a development of Lewes's ideas in Physiology, the passage below does not depart from the Physiology dramatically, and similar passages can be found in the earlier text. Lewes contributes a crucial frame for understanding Latimer's telepathy - that is, as a paradoxically physical transmission of thought and as a paradoxically local example of a phenomenon defined by immediacy across spatial gaps:

Let us now pass from Life to Mind. The vital organism we have seen to be evolved from the Bioplasm, and we may now see how the psychical organism is evolved from what may analogically be called the Psychoplasm. The Bioplasm is characterized by a continuous and simultaneous movement of molecular composition and decomposition.... [W] may say that the sentient material out of which all the forms of consciousness are evolved is the Psychoplasm incessantly fluctuating, incessantly renewed. Viewing this on the physiological side, it is the succession of neural tremors, variously combining into neural groups.... An organism lives only in relation to its medium. What growth is, in the physical sense, that is Experience in the psychical sense, namely, organic registration of assimilated material. (1874, 109-10)

Critics and historians concerned with Victorian psychology draw on such passages as evidence of efforts to write the mind in physical terms. In Victorian Psychology and 
British Culture, Rick Rylance cites the same passage from Lewes's text, noting that "the theoretical and descriptive homology between the two systems is essential, because the whole organic and mental entity is to be regarded as in immediate, continual, integrative, and enabling contact with the particular environmental medium in which it functions" (275). ${ }^{15}$ This interaction is central to The Lifted Veil, which is a literary experiment in the same principle. Eliot's understanding of the mind as, in the words of Michael Davis, "a whole composed of fluid, dynamic relations" and inseparable from its physical environment has dark implications in the atmosphere of London circa 1858 (7), when a very particular history of body-mind-environment interaction provides a novel meaning for the term "open-minded."

Unsanitary matter in a gaseous state threatens Latimer's tenuous sanity. His autobiography of telepathic experience mixes body and mind from the outset. Telepathy and prevision first come to Latimer after a period of illness and convalescence in Geneva, where his father sends him to complete an unwanted education in the natural sciences. An illness of the body affects Latimer's mental life. He begins to sense the inner life of those with whom he comes into contact, and to see future scenes. These twin talents are variable and unpredictable - he cannot command them at will, nor are they present continuously. Rather, like a chronic illness, they are involuntary and return in different ways depending on his context and time of life. As critics such as Helen Small note, The Lifted Veil figures telepathy as a disease of the body (xviii). From the outset, Latimer wonders whether his telepathy may be the effect of "the subtilising or exalting influence of some diseases on the mental powers," or of a disease "concentrating my energy of brain into moments of unhealthy activity," or of a "diseased consciousness" (10-14). Body and mind are shown to be related through this analogy to feverish delirium and other mental effects produced by bodily infection. Throughout the plot, Latimer's telepathy takes the form of prevision and of the direct and involuntary experience of the minds of those with whom he is in close proximity.

The rhetoric of telepathy - often drawn, as Beryl Gray and Martin Willis have shown, from contemporaneous reports $(409-10 ; 145-46)$ - combines with references to sanitation and pathology to render Latimer's experience as a feeling of sickening contagion. Throughout much of the story, his wife Bertha is the only person immune to his telepathy. But in the scene when Latimer does apprehend Bertha's body-mind, this clarity is "a moment of hell": "I saw into her pitiless soul - saw its barren worldliness, its scorching hate - and felt it clothe me round like an air I was obliged to breathe" (19). He figures telepathy as the involuntary inhalation of miasma. Read in the story's sanitary context, Bertha's vaporous consciousness is a source of contagion. Following this episode, Latimer is sick for several days. He describes the years following the unveiling as "sickening" (32). As is often the case in The Lifted Veil, this telepathy requires physical proximity; Latimer's telepathy is not as tele as many contemporaneous examples of telepathic and mesmeric experience at a distance. ${ }^{16}$ As Latimer's "diseased participation in other people's consciousness" torments him with the "weariness and disgust of this involuntary intrusion into other souls," the relation between sanitation and telepathy emerges unmistakably (17-18).

Telepathy in The Lifted Veil is as much a naturalistic matter of crossing the immunitary closure of the body as it is of supernatural mind reading. Latimer's mind is as open as his body to the vapors of waste and decay. The historical overlap of the Great Stink with sanitary reform and the twilight of miasma theory invites a symptomatic reading. Given the influence of contemporaneous materialist psychology on Eliot's work, The Lifted Veil 
represents telepathy circa the Great Stink of London as what Lewes calls the "organic registration of assimilated material" by the mind of a narrator involuntarily open to material sympathies $(1874,119)$. For Latimer, to use the term coined by Lewes before William James, the stream of consciousness has tributaries beyond the brain and outside the body altogether. ${ }^{17}$ This fluid-dynamic image corresponds all too well to Michael Rubenstein's suggestion, in my epigraph, that the antecedent to the stream of consciousness is the sewer (46).

The language used to describe Latimer's prevision of Prague also evokes sanitary crisis. This scene foreshadows much of the language through which the text figures Latimer's experience of other minds (or bodies). In the vision, Prague is old and decadent, eroded by centuries of decay. Its "blackened statues" seem to Latimer "the real inhabitants and owners of this place, while the busy, trivial men and women, hurrying to and fro, were a swarm of ephemeral visitants infesting it for a day" (9). Swarms are self-organizing groups of social insects, while ephemera can refer to insects that, in their winged form, live only for a day. Read in relation to the Great Stink (June 1858), which was almost simultaneous with Evans's and Lewes's visit to Prague (July 1858), this contemptuous double insect metaphor figures these people as breeding flies of the kind that would dine and reproduce in London's "fermenting heaps." For Latimer, flies replace human beings in a common scalar trope. He views these swarms from above, so that they become like the apian devils that shrink into Pandemonium in Paradise Lost, or the British as viewed by Martians in H. G. Wells's The War of the Worlds. The Prague passage dehumanizes the population, drawing much of its effect from the discourse of sanitary and sensory crisis.

Latimer's descriptions of telepathy and prevision trope humans as insects and refer to the literal insect denizens of waste heaps and city streets. Immediately after the Prague vision, Latimer begins to experience the thoughts of others. Without warning, "the vagrant, frivolous ideas and emotions of some uninteresting acquaintance... would force themselves on my consciousness like an importunate, ill-played musical instrument, or the loud activity of an imprisoned insect" (13). This insect commotion recalls the fly-citizens of Prague and evokes the fermenting heap cited earlier. In a text so engaged with the context of sanitation, any mention of insects also connotes the sense of smell.

These insects can be read in light of Barnes's account of class, odor, and sanitary reform: "as the deodorization of public space came to be associated with health, and perfumes signified refinement, foul smells (and that of excrement in particular) became an acute menace, emblematic of decay, disease, and the dangerous classes" (123). In The Condition of the Working Class in England (1845), Friedrich Engels describes Little Ireland in Manchester. Amid "masses of refuse, offal, and sickening filth" and an atmosphere "poisoned by the effluvia from these ... a horde of ragged women and children swarm about" (72). To return for a moment to the biographical, we remember Eliot's condescending reference to "cockneys" in her letter of 1857.

The stifling atmosphere of the Prague vision is reflected in Bertha's unveiling, Lewes's writing on respiration and suffocation, Eliot's letter of June 1857, and the fear of miasma during sanitary reform. Prague's insect polis worships "wearily in the stifling air of the churches" (9). During the years of sanitary reform, as historian Alain Corbin puts it, "to contemplate the mass of vapors that accumulated where living beings crowded together was to be seized with a vertiginous sense of alarm" (47). As a result, "this obsession with the crowding together of bodies later governed... the tactics that sanitary reformers 
used haphazardly in public space" (47-48). A passage from the chapter on air in Lewes's Physiology of Common Life, Vol. I is a likely influence on Eliot's description of the "stifling churches" of Prague. For Lewes, it is the "vitiation" of air by respiration - the replacement of oxygen with carbon-dioxide - that "makes the faces pale of those who issue from a crowded church, and gives a languor to those who have sat for some hours in a theatre, concert room, or any other ill-ventilated apartment, in which human beings have been exhaling carbonic acid from their lungs" (351). Latimer's vision of Prague relies on the affect of disgust at human proximity. Eliot superimposes the dark side of her ethics of sympathy on the crowded condition of cities that lack the infrastructure necessary to separate humans and animals from their waste.

While the words sanity and sanitation share a Latin root in sanus, their relationship in The Lifted Veil is more than etymological. Latimer fears the possibility of revealing his strange experiences to his family, especially to his father, "who would have suspected my sanity ever after" (13). Since he figures both the underlying cause and the process of telepathy in physical terms, Latimer's use of "sanity" also resonates at the level of sanitation and hygienic practice. As Diane Mason argues, Latimer's ailment, in the disciplinary regime of the Victorian bourgeoisie, suggests poor bodily discipline. For Mason, Latimer's telepathy is delusional. We can read it as an allegory of what were, for Eliot's contemporaries, the symptoms of "degenerate" masturbation. But as a literal account of telepathy, it is clear from Mason's reading and from evidence adduced here that Latimer's insanity is also the effect of unsanitary openness to external influence. ${ }^{18}$ More broadly, as Michel Foucault argues in Madness and Civilization, Anglo-European societies after the Enlightenment often stigmatize the "mentally" insane as unclean (72-73, 162-72). In Flesh in the Age of Reason, historian Roy Porter writes that, by the end of the eighteenth century in England, "the pursuit of health thus required the same sort of eternal vigilance as did the maintenance of the purity of the soul" (233). ${ }^{19}$ Meanings associated with mental and spiritual sanity were transferred to sanitation and encoded in practices calculated to maintain the purity of the body. The more-than-etymological conflation of sanity and sanitation is another source of body-mind ambiguity in Latimer's telepathy.

Latimer cements the physical character of his telepathy further by lamenting his permeable nature. Mixing his own consciousness with that of the bodies-minds that populate his environment creates a continuous "double," multiple, or "superadded" consciousness when Latimer is in the proximity of other characters $(21 ; 18) .{ }^{20}$ Reading The Lifted Veil only on the body-mind axis misses the complexity of the text's linguistic performance of consciousness, which is just as concerned with how body and mind (whatever their relation) interact with their physical environment. Latimer's unsanitary open-"mindedness" takes the form of a susceptibility to environment that agrees with Rylance's and Davis's accounts of the emphasis, in contemporaneous materialist psychology, on fluid exchange between mind and body, inside and outside - the same emphasis that we find in the passage from Lewes's Problems of Life and Mind cited above. Latimer's "nature was of the sensitive, unpractical order" - but then, his father raised him in an "uncongenial medium" (7). Latimer's permeability is in sharp contrast to the hermetic stasis of his father's personality, "a firm, unbending, intensely orderly man... one of those people who are always like themselves from day to day, who are uninfluenced by the weather" (5; my emphasis).

This reference to weather is a rich one in the atmosphere of London circa 1858. The question of relative openness or closure to the quality of the atmosphere adds evidence for the 
notion that the nexus of self and environment is as important as the body-mind relationship in The Lifted Veil. Latimer is the character type of a feminized, romantic "sensitive." As Anna Despotopoulou notes, he "embodies the characteristics of a classic gothic heroine with his romantic inclinations, his dreaminess, timidity, and fainting spells" (4). Latimer's feminine permeability contrasts with his father's sanguine, masculine physical boundaries. Thus Latimer's (unsanitary) open-mindedness corresponds to the figure of the spiritual medium, as Jill Galvan argues (241). But the imperviousness to atmospheric influence that Eliot uses to characterize Latimer's father is striking in light of Eliot's understanding of the mind in terms of what Davis calls "fluid, dynamic relations" (7). As a character and an unusual kind of unreliable narrator, Latimer is not Latimer, not as self-identical as his father, because he is much more open to the influence of his environment.

Sanitation played a major role in the consolidation of the limits of the bourgeois individual. In The Lifted Veil, the inscription of boundaries between self and other plays across the body-mind and body-environment axes. The dialectic of prophylaxis and contamination characterizes the self-narration of Eliot's only first person narrator apart from Theophrastus Such. From Mary Douglas, Julia Kristeva, and Michel Foucault, to the French historian of odor Alain Corbin, commentators note the importance of bodily purity, the affect of disgust, and abjection to the construction of selfhood and to social structure. If we consider the possibility, as many Victorian thinkers did, that there is no soul or mind separate from the workings of the body - that psychology collapses into physiology - then the contemporaneous scientific discourse concerning the permeability of the body to miasmas and microorganisms becomes all the more threatening. Now it is not only the mortal flesh that is susceptible to disease and decay, but also identity, thought, and language. These concerns are central to The Lifted Veil, narrated as it is by the victim of a "diseased consciousness" who experiences the thoughts of others involuntarily (14). Latimer often describes this experience in the language of contagion, invoking all of the senses, but emphasizing the sense of smell in such a way that his telepathy becomes a form of physical contact not just with other minds, but with other bodies. Sanitary discourse is thus the medium through which The Lifted Veil writes a mind that extends to the physical body and its immediate environment.

\section{The Odor of Thought}

ODOR IS NEGLECTED IN COMMENTARY on The Lifted Veil, but the text's figuration of telepathy often hinges on the sense of smell. Albrecht's observation that "the revelation of Bertha's antipathy" is "represented visually" is partial at best (444). Historians of odor such as Janice Carlisle and Alain Corbin explain the importance of odors fair and foul during the period of English and French sanitary reform. For Carlisle and Corbin, the sense of smell is unavoidable for histories of affect and class. It is not surprising that the sense of smell figures largely in the synaesthetic figurative patterns that merge the language of sanity and sanitation, body and environment in The Lifted Veil. The "hazy atmosphere of London environs" in Eliot's letter is experienced differently depending on social class, as the symbolic level of class distinction couples with the ambient environment - psychology with (eco)physiology (Haight 2: 338 39). "Stubbornly material," to use Carlisle's words, smell and odor require proximity, even physical contact (3). In this odor-historical context, Latimer's narrative enacts the literary problems inherent in a physical interpretation of mind by figuring telepathy in olfactory terms. 
In The Foul and the Fragrant, Alain Corbin studies the social history of odor during the period of The Lifted Veil's composition and setting. ${ }^{21}$ Corbin traces just over one hundred years of French olfactory history, from the middle of the eighteenth century through the end of the nineteenth, when the sanitation and deodorization of public and private space became prevalent. Though his focus is on France, his more general points about the period are transferable. Corbin links the history of romanticism and individualization to the flight from the putrid crowd and to aesthetic distance often mediated by perfumes that constituted a new "aesthetics of smell" (85). He discusses the odor-relation between the bourgeois individual and the crowd as an influence on sanitary reform:

The focus was on the deodorization of bodies and the environment in order to produce the sensory calm [the apparent opposite of Cohen's "sensory crisis" of the Great Stink] deemed indispensable to the voluptuous disturbances of the "I." Medical instructions for checking putrid fevers and stemming miasmas, the metaphysical anxiety engendered by the advance of putrefaction to the very depths of being, the rise of narcissism and the desire for physical access to scenes that it aroused, the wish to be perpetually on the alert to receive natural odors revealing the existence of the "I" and the harmony of the world, the fear aroused by social emanations that were still confused and undifferentiated - all these factors combined to promote the deodorization tactics put into effect from the mid eighteenth century on. These facts explain the lowering of the threshold for tolerance for stench, the emergence of a fashion for delicate perfumes, and the limited advance in bodily hygiene. (Corbin 85 ; my emphasis)

The emergence throughout the industrial revolution of a large and powerful middle class in England, the rapidly increasing urban populations, and the corresponding transformations of private space, meant that odor came to encode class hierarchy and bourgeois identity in new ways. During this period, as Cohen writes, "sanitation became equivalent with eliminating newly significant bad smells, both of individuals and places" (xviii). While it is difficult to point to one cause for the new significance of odor - density, individualism, class structure, the differential availability of sanitary technologies - scholarship on the history of odor and sanitation suggests that the social coding of odors foul and fair changed dramatically in eighteenth and nineteenth-century Europe. But Corbin's dramatic notion that putrefaction extends "to the very depths of being" invites a connection that he leaves aside: the meaning of sanitary crisis in a moment when not only the body, but also the mind and soul, begin to seem like material things subject to decay (85).

Janice Carlisle describes the role of olfactory politics in the work of Eliot and other writers. For her, signifying odors invest texts of this period par excellence, but it is the sense of sight that has received the lion's share of critical attention. "Unlike sight," Carlisle writes, "a sense whose functions are almost inevitably intellectualized, smell seems stubbornly material in both origin and effect" (3). Smell is associated with animality and with the material "substrate" of the human, disarticulated from soul, spirit, or any other exceptional vesicle that would link human animals with divinity and distinguish them from other life forms. Vision is synecdoche of reason and spiritual being. One does not smell the presence of an angel; a blaze of light or sound heralds the angel's presence. There is no need to rehearse arguments about the "occularcentrism," to use Martin Jay's term, of much epistemology and aesthetics. ${ }^{22}$ But this tradition offers some explanation of why commentators on The Lifted Veil stress the visual synecdoche of telepathy and why the notion of olfactory telepathy is 
counterintuitive, despite the fact that neither sight nor smell have a necessary relation to thought.

For Carlisle, the sense of smell "constitutes a basic - some might say, a negligible form of physical experience; but it is the sense that Victorian novelists frequently invoke to depict what happens when one character encounters another" (3). Though Carlisle does not comment on The Lifted Veil, her argument applies well to Eliot's experiment in the negative stakes of full sympathy with other bodies-minds in the context of atmospheric crisis. In Corbin and Carlisle both, the association of odor with identity, with socio-symbolic distinctions, and with private consciousness reinforces the importance of odor in the figurative structure of The Lifted Veil.

As the unsanitary atmosphere of thought intrudes upon Latimer's consciousness, The Lifted Veil refers telepathy to the sense of smell as often as to the sense of sight or hearing. Bertha's unveiling is one of the strongest examples of this point; Eliot's title leaves little doubt about the scene's importance. When Bertha's thoughts are finally revealed to Latimer, he feels them "clothe me round like an air I was obliged to breathe" (19). In a "moment of hell," his dubious gift unveils her "barren worldliness" to him for the first time (19). For Albrecht, Bertha is a "femme fatale whose outer beauty has veiled her inner monstrosity" (439). As Sandra M. Gilbert and Susan Gubar have argued, Latimer's misogynistic typing of Bertha associates her with serpents, Cleopatra, and thus metonymically with the mud of the Nile (460-61). Latimer describes the unveiling as an exposure of base materiality, the opposite of the poetic visions he hopes for throughout the plot. She becomes an inescapable odor, that "clothes" the narrator and so constitutes the immediate environment of his embodied mind. Earlier in the story, when Latimer first feels Bertha's gaze in a prevision, he has "a painful sensation as if a sharp wind were cutting me" (11). In an atmospheric figure that uses odor as medium to describe telepathy, the "sharp wind" of her "gaze" foreshadows her ultimate unveiling.

The involuntariness of Latimer's perception of Bertha's atmospheric body-mind points to the sense of smell as the vehicle of his telepathy - vehicle in the sense of both perfumery and rhetoric. Smell is the most involuntary of the senses and the one most difficult to block. We can close our eyes and plug our ears, but we still need to breathe. Combined with the telepathic contacts figured in terms of sickness, disgust, and contagion described in the previous section, this obligatory air that characterizes Bertha's unveiling affirms the role of odor in the The Lifted Veil.

Proximity is necessary for odor, taste, and touch in a way that it is not for sight and sound. In The Lifted Veil, proximity is a constant factor in Latimer's telepathy. This is a paradoxical point given that non-locality is usually central to telepathy, as the prefix tele-suggests. While Latimer's prevision enables visions of spatially as well as temporally distant scenes, his telepathy entails the "obtrusion" on his "mind" or "consciousness" of the "mental process going forward in first one person, and then another, with whom I happened to be in contact" (13; my emphasis). On the Grand Terrace at the Belvedere Gallery in Vienna, he makes a point of avoiding "the proximity of the sentinel" so as not to be subjected to the sentinel's thoughts (19). Late in life, Latimer lives in near solitude, seeking "relief from wearisome insight" into the minds of others (36). Beryl Gray, Martin Willis, and Thomas Albrecht, who take telepathy as a central topic, do not address this strange need for physical proximity on the part of a phenomenon that is so often non-local, as it is in Myers's 1882 definition. Latimer's telepathy is material connection - not a form of immaterial perception, as emphasis on the 
sense of sight would lead us to believe. The need for proximity in Latimer's telepathy also supports my emphasis on odor, which allows us to read the veil as a barrier to contagion. The role of proximity in Latimer's telepathy also echoes Eliot's mention, in the letter of 1857, of unwashed bodies, crowded conditions, and the desire for green prophylaxis.

Recounting the episode in Vienna, Latimer narrates another example of olfactory telepathy. On vacation with Bertha and his family at the Lichtenberg Palace, the "cunning, relentless face" of Giorgione's Lucrezia Borgia captivates him. Once again, his relationship to this influence is involuntary. He feels "a strange poisoned sensation, as if I had long been inhaling a fatal odour, and was just beginning to be conscious of its effects" (19; my emphasis). The rumor about Borgia, of course, is that she secretly poisoned her men. This scene is a prevision of Bertha's own plan to poison Latimer. But the involuntary, subliminal character of the odor alludes to the miasma theory of disease and the vapors of the urban milieu. Kirstie Blair emphasizes similar figures in Middlemarch, where Lydgate's marriage begins "to seem like a form of pollution," and pollution is "a concept both etymologically and metaphorically linked to infection" (148). As he leaves the gallery for the gardens, Bertha quietly intercepts Latimer and links her arm with his. In close proximity with Bertha, Latimer experiences the "continuance or climax of the sensation I was still feeling from the gaze of Lucrezia Borgia" (19). This time, he is struck with a prevision of his married life with Bertha and of her final unveiling. Here Latimer seems transported physically into the future, as if in a reversal of the well-known interplay of odor and memory. This scene figuratively combines the senses of smell, touch, and sight in rendering Latimer's prevision. The scene also shows the importance of physical proximity and miasma to Latimer's gift. The double reference of this "fatal odor" to consciousness - it is both a figure for prevision in general and prevision figured as an odor just creeping above the threshold of the conscious mind establishes the scene on the terrace as a scene of olfactory telepathy. Like the sense of smell, the direct transmission of thought demands proximity.

The same scene makes vegetable odor a prophylaxis against olfactory telepathy - a prophylaxis that needs to be, like Bertha's veil, a barrier to thought as a well as to unsanitary matter. Invoking the perfume of plants, The Lifted Veil registers the historical transition from the use of animal to the use of vegetable perfumes. Unable to look at any other pictures for fear of further chafing his "diseased sensibility," Latimer does not accompany the others into the Belvedere Gallery, but instead wanders in the "trim gardens" $(20,19)$. His effort to find shelter from the "fatal odor" in a place of vegetable perfume repeats Latimer's defense against his first and second visions: the vision of the fly-citizens and foul air of Prague and the vision of Bertha's unveiling that immediately precedes their first meeting. In those scenes, Latimer recovers by using eau-de-Cologne; he rubs "the reviving spirit over my hands and forehead, and under my nostrils" (12; my emphasis). Lighter and more diluted than perfume, eau-de-Cologne is made from citrus or other botanical oils. Thus Latimer tries to counteract his olfactory telepathy by interposing the odor of a plant. Moreover, during the period when he is still immune to Bertha's interiority, he uses the word "green" three times in a sentence that describes her physical appearance (11-12).

As Corbin notes, it was during the early nineteenth century, during the rise of sanitary reform, that flower gardens and floral perfumes came to offer escape from the prevalence of dangerous mammalian miasmas in confined urban spaces (190). Vegetable odors played a new role in the care of the self and the aesthetics of class. For Corbin, the social re-coding of odor led to the "condemnation of the use of musk, ambergris, and civet," all of which are 
perfumes derived from mammals - that is, from glands near the genitals of deer or civet, and from the intestines of sperm whales (74). All were extremely popular perfumes, but through the late-eighteenth and early-nineteenth centuries, their animal origins began to provoke disgust. Floral perfumes replaced animal perfumes in emerging hygiene rituals. For Latimer, botanical essences are a means of blocking his involuntary openness to animal thought miasmas. Acting as a prophylaxis for consciousness in a text that materializes consciousness and often figures it in olfactory terms, the botanical references in The Lifted Veil gesture to the possibility that plants shape mind through odor as well as through more clear-cut examples such as the ingestion of coffee, opium, or the "hashish" that Latimer uses as metaphor for Bertha's flattering rhetoric (29).

Smell is already touch. While all five senses involve some kind of physical contact with waves of electromagnetic radiation, with mechanical waves of sound, with things that excite nerves in the skin, with things that excite taste receptors in the mouth - odor, like taste, requires physical contact with molecules cast off by the source of the odor itself. This fact raises the stakes for Latimer's experience of telepathy as sanitary danger. Odor involves physical contact with that which it senses, but different from taste and touch the source of the sensation is not always apparent. This point adds another dimension to the paradoxical character of telepathy in the story, which combines both proximity and the absence entailed by the prefix tele-.

The association of odor and prevision may be a translation of the link between odor and memory, which Lewes discusses in the third volume of Problems of Life and Mind, and which plays an oft-cited role in Proust. Lewes shows his awareness of this mnemonic, which offers a different gloss on the relationship of odor and tele-presence, in an anecdote: "Some years ago I was watching the gambols of two tigers, when one of them suddenly ejected his urine full in my face. The stench was indescribable, and so violently did it affect me that for several weeks I was constantly plagued by a recurrence more or less vivid of the sensation ... for some time after it had left me, any scent having the slightest resemblance to it sufficed to revive the memory" $(1879,298)$. In this scene, direct contact with mammalian waste, proximity, and memory come together to bridge the gap between consciousness and the body. Odor serves as the vehicle, long after the odor proper has vanished, for the non-local presence of the object of disgust. The Lifted Veil unfolds this paradoxical relation of odor and touch, tele-presence and immediate contact through a figurative structure that mixes the language of mental communion, sanitation, and physical disease.

The emphasis on odor throughout the story reinforces the importance of the sanitary context for the interpretation of Eliot's gothic science-fiction experiment. Returning to the "fermenting heap" that figures Latimer's direct perception of other bodies-minds, emphasis on odor allows us to think telepathy as the "organic registration of assimilated material," to use Lewes's phrase $(1874,109)$. In the same passage, Latimer describes the mannered, prophylactic veils of those whose thought he perceives using the image of the web, an image which draws us into biological networks of capillaries and neural ganglia, just as it extends outward to the mind's environment. Eliot and Lewes frequently employ this image, which is much discussed in Eliot criticism. Sally Shuttleworth argues that "the image of the web is one employed by Lewes to define the psyche; to demonstrate the impossibility of a division between organism and environment, self and other" in "the complex interlocking of social and psychic meshes" (194). ${ }^{23}$ The fermenting heap and other scenes of telepathy that rely overwhelmingly on the language of sickness, disgust, disease, odor, 
bad air, atmosphere, wind, "uncongenial medium," hygiene, horror, (in)sanity, pollution, insect swarming, perfume, and poison show that Eliot's story uses the context of sanitary crisis as a medium in which to work out the competing claims of materialist science and "pseudoscience" about the relations among body, mind, and environment.

THE STREAM OF CONSCIOUSNESS LEAKS. The Lifted Veil unfolds between two scenes of harsh reification: the phrenologist's examination of Latimer's skull at the beginning of the story and the blood transfusion that functions as a climax. The transfusion scene represents a flow between bodies - a flow of blood, but one that seems, as Kate Flint argues, to endow Bertha's servant Mrs. Archer with the masculine socio-symbolic authority necessary to reveal Bertha's plot to poison Latimer; a flow of something unsanitary and material that nevertheless, in Latimer's words, restores the dead Mrs. Archer's "soul" and "spirit of life" (41-42). We can thus read the transfusion scene that closes The Lifted Veil as a travesty of The Lifted Veil, a brief allegory of Latimer's telepathy nested in his own narrative. Yet the transfusion scene may be a guide how not to read the story, a guide which suggests that neither an eliminative materialism of the brain nor one of circulating environmental matter is enough. What is missing from the transfusion scene is the more difficult experiment that The Lifted Veil, as a whole, attempts: writing consciousness as physical in a way that eschews dualism, but without embracing reductionism. What this reading clarifies is the paradoxical relation between the stark materialism of the story's theory of mind - pressed home by the focus on sanitary crisis throughout the text's figurative structure - and the supernatural implications of Latimer dubious gift. The transfusion experiment is a travestied replication of the narrative experiment.

In this context, experiment means an effort to transform language in a figurative crucible, which is unavoidable when we realize that efforts to understand the body-mind relation mire in problems of writing. Writing of Lewes, Rylance describes this kind of experiment as "a performance in language and a performance on language" (310) The Lifted Veil is an experiment in this sense. Combining telepathy and sanitation, the story explores the complexity of the body-mind-environment problem without falling into the linguistic trap of choosing one side of this three-part distinction, then imagining the side selected to be most true to nature. The relation Eliot establishes between telepathy and sanitation is a means of keeping this distinction at play. As Lewes seems to ask in The Physiology of Common Life, how much of the body thinks? (12-13). As he puts it in Problems of Life and Mind, how much of the body is "sentient material"? (1874, 109; my emphasis).

The Lifted Veil asks what it means to make mind physical in a way that does not insist on a brutal reduction to the matter of the brain. In this way, Eliot's story corresponds closely to Lewes's non-reductionist naturalism in Problems of Life and Mind. The couple's seemingly paradoxical materialism might explain why Eliot's story combines such disparate phenomena as telepathy and sanitation. However materializing its focus on sanitary and olfactory significations might be, the story maintains its distance from reduction techniques such as phrenology - which is dismissed, early on, as an ill-advised paternal imposition. However many connections we are able to find between The Lifted Veil and contemporaneous materialist psychology, the text is nevertheless about telepathy, about a phenomenon of consciousness, about non-local messaging unexplainable in material terms. Readings of The 
Lifted Veil that understand Latimer as simply an unreliable narrator, and explain away his telepathy, run up against the story's many efforts to show that his supernatural ability has real effects and makes real predictions. If the phrenology scene is too individual, reifying Latimer in the map of his brain, the transfusion scene is too material, misrecognizing blood as mind. The Lifted Veil attempts a path between the Scylla and Charybdis of these two approaches to mind. The stream of consciousness is neither individual nor strictly material - at least if we think of materialism in what is ultimately a reductive, eliminative, or atomistic mode. Rylance's strong account of Lewes position in Problems puts it well: Lewes simultaneously refused an "ontological distinction between physical and mental acts" and "contested the militant materialism of 'automatists' such as Huxley and Tyndall" (285; 283). This contradictory sort of materialism both characterizes Eliot's story and resembles recent statements of a "new" materialism that posits irreducible levels of activity, such as the level of mind, which are material yet non-mechanistic and causally indeterminate.

Future criticism might also read The Lifted Veil ecocritically, as a text about environmentality which nevertheless has little to do with nature writing. ${ }^{24}$ As Jesse Oak Taylor argues in a reading of Bleak House entitled "The Novel as Climate Model," texts that address the animal and industrial pollution of London might now, in the era of climate change, become a means of understanding formal and affective responses to changes in weather and climate. As a fascinating example of environmental influence upon thought and of thought as environmental, The Lifted Veil might also become a text of interest for critics concerned with the means by which weather and climate become subjective in this moment when anthropogenic climate has become dangerous and political. As an early experiment in the implosion of body, mind, and environment in a polluted context, Eliot's story and the broader interaction of her work with the work of Lewes may eventually be situated in the canon of Victorian ecocriticism.

Rice University

\section{NOTES}

I owe gratitude to my friends Evan Morson-Glabik, Jon Hilderman, Daniel Adelman, Scott Innis, and Abby Goode for their conversation about this topic. I am especially indebted to Suzy Anger for her encouragement and multiple readings of the essay.

1. As Gray puts it, in a slightly different vein, "it was from the earlier milieu, with its preoccupation with the pseudosciences, that George Eliot was to draw the material for 'The Lifted Veil.' Ironically, it was perhaps the relationship with Lewes - who admired the story from the beginning, describing it as being 'of an imaginative philosophical kind, quite new and piquant' ...- which enabled her to achieve the necessary distance from the material to employ it fictionally" (423).

2. In narrating telepathy as a curse, The Lifted Veil is similar to science-fiction writer LeGuin's story Vaster than Empires and More Slow (1971).

3. I mean naturalism in the philosophical sense: a worldview for which nature is the only reality and there are no supernatural or transcendental (whether in a theist or Kantian sense) entities. The naturalism of The Lifted Veil is then paradoxical, because it imagines a supernatural phenomenon, telepathy, in naturalistic terms.

4. Perhaps The Lifted Veil anticipates the work of Lovecraft. Lovecraft's "weird" aesthetic is often attributed to the fact that he writes naturalistic, rather than supernatural, horror. See for example 
Thacker, In the Dust of this Planet: Horror of Philosophy Vol. 1 and Harman, Weird Realism: Lovecraft and Philosophy.

5. Frank highlights a naturalistic version of mesmerism in "Valdemar's Tongue, Poe's Telegraphy," where he discusses mesmerism as a figure for electromagnetic telegraphy. Though different from telepathy, this interpretation of mesmerism is comparable to Eliot's account of telepathy as transmission of unsanitary matter.

6. See, for example, Alaimo and Hekman, Material Feminisms, and DeLanda, Virtual Science and Intensive Philosophy. Much in this new materialism is grounded in concepts of emergence that have their provenance in late nineteenth-century British philosophy and in eighteenth-century French Materialism. For an overview, see DeLanda "Emergence, Causality, and Realism." For an older, and classic statement of new materialism less influenced by the philosophy of Deleuze, see Prigogine and Stengers, Order Out of Chaos: Man's New Dialogue with Nature.

7. The study of fermentation was central to Louis Pasteur's research that culminated in the articulation of the germ theory of disease. For Otis in Membranes: Metaphors of Invasion in Nineteenth Century Literature, Science, and Politics, "Pasteur had moved on to studies of fermentation after ten years (1847-57) of studying how organic substances rotated polarized light. By 1858, he had convinced himself and many other scientists that 'ferments, properly called, are living beings . . the germs of microscopic organisms abound on the surface of all objects, in the atmosphere and in the water"' (26). Although it is likely that Lewes, and perhaps also Eliot, would have been aware of Pasteur's work by the time Eliot wrote The Lifted Veil, the model of contagion most relevant to Latimer's telepathy is the miasma. O'Leary discusses germ theory in Victorian literature in "Germ Theory Temporalities and Generic Innovation in Neo-Victorian Fiction." Blair discusses contagion in relation to Eliot's poetics of sympathy in "Contagious Sympathies: George Eliot and Rudolf Virchow."

8. The passage appears in Lewes, The Physiology of Common Life, Vol. I, 254.

9. The opening point of Halliday's The Great Stink of London: Joseph Bazalgette and the Cleansing of the Victorian Metropolis is that the Great Stink's penetration of Parliament motivated the members to fund a "sanitation system of unprecedented scale and complexity which changed London forever," a system which included Bazalgette's Thames Embankment (ix).

10. As Weinreb and Hibbert write in The London Encyclopedia, St. John's Wood was a neighborhood of inner northwest London that attracted Victorian intellectuals: "the variety and charm of the comparatively inexpensive houses ... and the convenience of its proximity to Central London, combined with the purity of the air made this an area chosen and inhabited by artists, authors, philosophers and scientists" (747; my emphasis).

11. Taylor and Shuttleworth collect many strong examples in Embodied Selves: An Anthology of Psychological Texts, 1830-1890. They focus on "the various forms of materialist science of the self which rejected the dualistic division between mind and body, conceiving both the body and the mind in diverse and complex ways, and which was at once fascinated and perturbed by those hidden inner regions that remained beyond conscious control" (xiv).

12. As Shuttleworth reminds us in George Eliot and Nineteenth Century Science, "Victorian science was not ... a unified body of knowledge, but rather a diffuse collection of disciplines divided internally by competing theories and intellectual schisms" (x).

13. For example: "Psychology is the science of mind; physiology is the science of life. All who recognize the former as a science, take its goal to be the elucidation of the laws of thought, the nature of the soul, and its prerogatives. This science may seek - and I follow those who think it ought to seek - important means of investigation in the laws of physiology; just as physiology itself must seek important aids in chemistry and physics" (Lewes 1859, 10). Lewes goes on to suggest that there are nevertheless psychological facts that physiology cannot explain, which points to my conclusion that mind in The Lifted Veil is physical, but irreducible.

14. We seem to need this reminder since, as Menely notes, in literary history air is commonly a figure of immateriality. He draws our attention to Samuel Moore's rendering of Marx's German as "all 
that is solid melts into air," a translation based on Prospero's soliloquy at the end of The Tempest (95).

15. Davis argues, in similar terms, for the influence of this conception of body-mind-environment interaction on Eliot's fiction: "regarded as an integral part of the life of the organism, the mind must be open to the influence of inward physical processes and mechanisms, of environmental conditions and of interactions with other organisms" (5).

16. Including Myers's definition of telepathy in 1882: "we venture to introduce the words telesthesia and telepathy to cover all cases of impression received at a distance without the normal operation of the recognized sense organs" (147).

17. Problems of Life and Mind: "There is thus a stream of consciousness formed out of the rivulets of excitation, and this stream has its waves and ground swell: the currents are continuous and blend insensibly; there is no breach or pause" (3: 366). See also Bateson, Steps to an Ecology of Mind (319).

18. While critics such as Mason and Eagleton argue that Latimer is an unreliable narrator, that his telepathy is imagined, these readings must ignore Latimer's failed efforts to disprove his own telepathy. As Gray argues, readings that purge the text of paranormal phenomena must work against the text's earnest tone and lack of satire; they reflect earlier efforts to ignore The Lifted Veil altogether, or quarantine it from Eliot's realist work (408). Such readings must also rely on the unproveable prior assumption that Latimer could always, for all we know, be lying.

19. Conflation of sanity and sanitation continues in sanitary discourse of a later period, when sanitary regimes were more fully consolidated in industrialized nations. In Sanitation and Physiology (1910), Ritchie writes that "Sanity and sanitation mean the same in their origin, and we might conclude that to practice sanitation is to act sanely and sensibly, while not to practice it is to act in a way that indicates either a lack of knowledge or a lack of wisdom" (144). And in the Rockefeller Foundation's A Review for 1920: Public Health and Medical Education in Many Lands, we hear that "control of typhoid fever, or malaria, or yellow fever is not so much an end in itself as a means of setting up a permanent organization which will gradually extend the scope of its work from the installation of latrines and water supplies to the control of communicable diseases and ultimately even mental hygiene, i.e., from sanitation to sanity" (38-39). This passage appears in a section entitled "From Sanitation to Sanity."

20. Perhaps Latimer is a strange species of "unreliable" narrator, since we can never be sure how many others might already have been present in the past states of consciousness that Latimer, drawing nearer to this death, narrates as his own. Galvan makes a similar point (246).

21. Corbin's study is also a source for the German novelist Süskind's Perfume, adapted for film in 2006, which might be considered a novel of olfactory telepathy, or at least of incredibly heightened, non-local smell. The film's biggest failing is its constant effort to portray this sense visually, through close-ups of the protagonist's nostrils.

22. In a similar vein, Corbin enumerates some of the demotions suffered by the animal sense: "The sense of smell was discredited . . . Kant excluded it from aesthetics. Physiologists later regarded it as a simple residue of evolution. Freud assigned it to anality. Thus discourse on odours was interdicted. But the perceptual revolution, precursor of our odourless environment, can no longer be suppressed" (229).

23. For more on Victorian web imagery, see Beer, Darwin's Plots (156-57).

24. Much recent ecocriticism turns away from nature writing and from uses of the concept of nature that depend on its normative separation from culture. In "The Novel as Climate Model," Taylor studies the "abnatural" atmosphere of Victorian London. In Ecology without Nature: Rethinking Environmental Aesthetics, Morton argues that we should abandon the concept of nature in order develop a critical ecological thought. In Bodily Natures, Alaimo coins the term transcorporeality to mark how human bodies are always materially continuous with their ecological contexts. For more on Victorian atmosphere, see Taylor's This Sky of Our Manufacture. 


\section{WORKS CITED}

Alaimo, Stacy. Bodily Natures: Science, Environment, and the Material Self. Bloomington: Indiana UP, 2010.

Alaimo, Stacy, and Susan Hekman. Material Feminisms. Bloomington: Indiana UP, 2008.

Albrecht, Thomas. "Sympathy and Telepathy: The Problem of Ethics in George Eliot's The Lifted Veil." English Literary History 73.2 (2006): 437-63.

Allen, Michelle. Cleansing the City: Sanitary Geographies in Victorian London. Athens: Ohio UP, 2008.

Barnes, David. "Confronting Sensory Crisis in the Great Stinks of London and Paris." Filth: Dirt, Disgust, and Modern Life. Ed. William A. Cohen and Ryan Johnson. Minneapolis: U of Minnesota P, 2005. 103-32.

Bateson, Gregory. Steps to an Ecology of Mind. 1972. Chicago: U of Chicago P, 2000.

Beer, Gillian. Darwin's Plots: Evolutionary Narrative in Darwin, George Eliot, and Nineteenth-Century Fiction. Cambridge: Cambridge UP, 2000.

Blair, Kirstie. "Contagious Sympathies: George Eliot and Rudolf Virchow." Unmapped Countries: Biological Visions in Nineteenth Century Literature and Culture. Ed. Anne-Julia Zwierlein. London: Anthem P, 2005. 145-154.

Bourne-Taylor, Jenny, and Sally Shuttleworth. Embodied Selves: An Anthology of Psychological Texts, 1830-1890. New York: Oxford UP, 1998.

Carlisle, Janice. Common Scents: Comparative Encounters in High Victorian Fiction. Oxford: Oxford UP, 2004. vii-xxxvii.

Chadwick, Edwin. Report on the Sanitary Condition of the Laboring Population of Great Britain. London: W. Clowes and Sons, 1843.

Choi, Tina Young. "Writing the Victorian City: Discourses of Risk, Connection, and Inevitability." Victorian Studies 43.4 (2001): 561-89.

Cohen, William A. "Introduction: Locating Filth." Filth: Dirt, Disgust, and Modern Life. eds. William A. Cohen and Ryan Johnson. Minneapolis: U of Minnesota P, 2005.

Corbin, Alain. The Foul and the Fragrant: Odor and the French Social Imagination. Cambridge: Harvard UP, 1986.

Davis, Michael. George Eliot and Nineteenth Century Psychology: Exploring the Unmapped Country. Burlington: Ashgate, 2006.

DeLanda, Manuel. "Emergence, Causality, and Realism." The Speculative Turn: Continental Realism and Materialism. Ed. Levi Bryant, Nick Srnicek, Graham Harman. Melbourne: Re.Press, 2011. 381-92.

- Intensive Science and Virtual Philosophy. New York: Continuum, 2002.

Despotopoulou, Anna. "Gender Transfusions in George Eliot's 'The Lifted Veil.'” George Eliot-George Henry Lewes Studies 58-59 (2010): 2-19.

Douglas, Mary. Purity and Danger. London: Routledge and Keegan Paul, 1966.

Eagleton, Terry. "Power and Knowledge in The Lifted Veil." Literature and History 9.1 (1983): 52-61.

Eliot, George. The Lifted Veil and Brother Jacob. Ed. Helen Small. Oxford: Oxford UP, 1999.

Engels, Friedrich. The Condition of the Working Class in England. 1845. Ed. David McClellan. Oxford: Oxford UP, 1993.

The Fantastic Voyage. Dir. Richard Fleischer. Twentieth Century Fox, 1966. Film.

Flint, Kate. "Blood, Bodies, and The Lifted Veil." Nineteenth-Century Literature 51.4 (1997): 455-73.

Foucault, Michel. Madness and Civilization. 1961. Trans. Richard Howard. New York: Vintage, 1988.

- Power/Knowledge: Selected Interviews and Other Writings. 1974. Ed. Colin Gordon. New York: Harvester, 1980.

Frank, Adam. "Valdemar's Tongue, Poe's Telegraphy." English Literary History 72.3 (2005): 635-62.

Galvan, Jill. "The Narrator as Medium in George Eliot's 'The Lifted Veil.'” Victorian Studies 48.2 (2006): 240-48. 
Gamow, George and Martynas Ycas. Mr. Tompkins Inside Himself: Adventures in the New Biology. New York: Viking, 1967.

Gilbert, Pamela K. "Medical Mapping: The Thames, the Body, and Our Mutual Friend." Filth: Dirt, Disgust, and Modern Life. Ed. William A. Cohen and Ryan Johnson. Minneapolis: U of Minnesota P, 2005. 78-102.

Gilbert, Sandra M., and Susan Gubar. The Madwoman in the Attic: The Woman Writer and the NineteenthCentury Literary Imagination. 1979. New Haven: Yale UP, 2000.

Gray, Beryl. "Pseudoscience and George Eliot's 'The Lifted Veil.'” Nineteenth-Century Fiction 36.4 (1982): 407-23.

Haight, Gordon. The George Eliot Letters. New Haven: Yale UP, 1954.

Halliday, Stephen. The Great Stink of London: Sir Joseph Bazalgette and the Cleansing of the Victorian Capital. Phoenix Mill: Sutton, 1999.

Harman, Graham. Weird Realism: Lovecraft and Philosophy. Winchester: Zero Books, 2012.

Jay, Martin. "The Rise of Hermeneutics and the Crisis of Ocularcentrism.” Poetics Today 9.2 (1988): 307-26.

Kristeva, Julia. Powers of Horror. 1980. Trans. Leon S. Roudiez. New York: Columbia UP, 1982.

Le Guin, Ursula K. "Vaster than Empires and More Slow." Four Ways to Forgiveness. New York: Harper, 2004.

Lewes, George Henry. Problems of Life and Mind: First Series: The Foundation of a Creed. Vol I. London: Trubner, 1874. Web. 14 Nov. 2014.

- Problems of Life and Mind: Third Series. London: Trubner, 1879. Web. 14 Nov. 2014.

- The Physiology of Common Life, Volume II. 1859. New York: D. Appleton, 1875.

Mason, Diane. "Latimer's Complaint: Masturbation and Monomania in The Lifted Veil." Women's Writing 5.3 (1998): 393-403.

Menely, Tobias. “Anthropocene Air.” the minnesota review 83 (2014): 93-101.

Milton, John. Paradise Lost. 1667. New York: D. Appleton, 1850.

Morton, Timothy. Ecology without Nature: Rethinking Environmental Aesthetics. Cambridge: Harvard UP, 2007.

Myers, F. W. H. "Human Personality.” Proceedings for the Society of Psychical Research 1.2 (1882): 147. Web. 10 Feb. 2015.

O’Leary, Joanna Shawn Brigid. "Germ Theory Temporalities and Generic Innovation in Neo-Victorian Fiction.” Neo-Victorian Studies 6.1 (2013): 75-104. Web. 10 Feb. 2015.

Otis, Laura. Membranes. Baltimore: Johns Hopkins UP, 1999.

Perfume: The Story of a Murderer. Dir. Tom Tykwer. DreamWorks Pictures, 2006. Film.

- Flesh in the Age of Reason. London: Allen Lane, 2003.

Prigogine, Ilya, and Isabelle Stengers. Order Out of Chaos: Man's New Dialogue with Nature. London: Flamingo, 1985.

Ritchie, John. Sanitation and Physiology; Being Primer of Sanitation and Human Physiology in One Volume. New York: World Book., 1910. Web. 15 Feb. 2011.

Royle, Nicholas. Telepathy and Literature: Essays on the Reading Mind. Cambridge: Blackwell, 1990.

Rubenstein, Michael. Public Works: Infrastructure, Irish Modernism, and the Postcolonial. Notre Dame: U of Notre Dame P, 2010.

Rylance, Rick. Victorian Psychology and British Culture, 1850-1880. Oxford: Oxford UP, 2000.

Shuttleworth, Sally. George Eliot and Nineteenth-Century Science: The Make-Believe of a Beginning. New York: Cambridge UP, 1984.

- Introduction. The Lifted Veil; Brother Jacob. New York: Penguin, 2001.

Small, Helen. Introduction. George Eliot. The Lifted Veil and Brother Jacob. Oxford: Oxford UP, 1999.

Süskind, Patrick. 1985. Perfume: The Story of a Murderer. Trans. John E. Woods. New York: Knopf, 1987.

Taylor, Jesse Oak. "The Novel as Climate Model: Realism and the Greenhouse Effect in Bleak House." Novel: A Forum for Fiction 46.1 (2013): 1-25. 
. The Sky of Our Manufacture: The London Fog in British Fiction from Dickens to Woolf. Charlottesville: U of Virginia P, 2016.

Thacker, Eugene. In the Dust of this Planet: Horror of Philosophy, Vol. 1. Washington: Zero, 2011.

Viera, Carroll. “'The Lifted Veil' and George Eliot's Early Aesthetic.” Studies in English Literature 24 (1984): 749-67.

Vincent, George E. A Review for 1919: Public Health and Medical Education in Many Lands. New York: The Rockefeller Foundation, 1920.

Weinreb, Ben, and Christopher Hibbert. The London Encyclopedia. London: Macmillan, 1993.

Wells, H. G. The War of the Worlds. 1898. New York: Penguin, 2005.

Willis, Martin. "George Eliot's The Lifted Veil and the Cultural Politics of Clairvoyance." Victorian Literary Mesmerism. Ed. Martin Willis and Catherine Wynne. Amsterdam: Rodopi, 2006.

Wolfreys, Julian. "Phantom Optics: Contextualising The Lifted Veil." George Eliot-George Henry Lewes Studies 38-39 (2000): 61-75. 